\title{
Dinámicas socioecológicas y ecoturismo comunitario: un análisis comparativo en el eje fluvial Guayabero-Guaviare*
}

Cómo citar este artículo: Del Cairo, C., Gómez Zúñiga, S., Ortega Martínez, J. E., Ortiz Gallego, D., Rodríguez Maldonado, A. C., Vélez Triana, J. S., y Vergara Gutiérrez, T. (2018). Dinámicas socioecológicas y ecoturismo comunitario: un análisis comparativo en el eje fluvial Guayabero-Guaviare.Cuadernos de Desarrollo Rural, 15 (82), I-23. https://www.doi.org/I0.III44/Javeriana.cdri5-82.dsec

Carlos Luis del Cairo

Pontificia Universidad Javeriana, Colombia

cdelcairo@javeriana.edu.co

ORCID: http://orcid.org/0000-0002-6782-9273

Sebastián Gómez Zúñiga

Centro de Alternativas al Desarroll, Colombia

ORCID: http://orcid.org/0000-0003-2884-470X

Juan Eduardo Ortega Martínez

Centro de Alternativas al Desarrollo, Colombia

ORCID: http://orcid.org/0000-0002-5255-833

Daniel Ortiz Gallego

Centro de Alternativas al Desarrollo, Colombia

ORCID: http://orcid.org/0000-0002-526I-0615

Angie Carolina Rodríguez Maldonado

Universidad del Rosario, Colombia

ORCID: http://orcid.org/0000-0002-8605-0943

Juan Sebastián Vélez Triana

Pontificia Universidad Javeriana, Colombia

ORCID: http://orcid.org/0000-0003-3259-4627

Tomás Vergara Gutiérrez

Pontificia Universidad Javeriana, Colombia

ORCID: http://orcid.org/0000-0002-7838-7562

DOI: https://doi.org/I0.III44/Javeriana.cdri5-82.dsec

Redalyc: http://www.redalyc.org/articulo.oa?id=II757724006

Recibido: 30 marzo 2018 I Publicación: I8 Diciembre 2018 


\title{
Resumen:
}

Los efectos del ecoturismo en las relaciones entre habitantes y su entorno son complejos y multidimensionales. Para explorar estos efectos, se analizan comparativamente dos iniciativas ecoturísticas comunitarias del departamento del Guaviare, un territorio históricamente afectado por el conflicto armado y hoy priorizado como escenario de construcción de paz. El análisis articula enfoques de la ecología política y de los sistemas socioecológicos y destaca la pertinencia de comprender las relaciones de poder que emergen en contextos de ecoturismo comunitario que, a su vez, ayudan a dimensionar la manera en que este tipo particular de turismo incide en las dinámicas socioecológicas y en las estrategias de familias campesinas que buscan diversificar sus economías en clave sostenible.

Palabras clave: ecología política, sistemas socioecológicos, ecoturismo comunitario, comunidades campesinas, Colombia, Amazonia, Guaviare.

\section{Socio-Ecological Dynamics and Community Ecotourism: A Comparative Analysis in the Guayabero-Guaviare River Axis}

\begin{abstract}
:
The effects of the ecotourism in the relationships between inhabitants and their environment are complex and multidimensional. To explore these effects, two community ecotourism initiatives in the Guaviare Province were comparatively analyzed. This territory has been historically affected by the armed conflict and today is given priority as a scenery for the peace construction. The analysis herein articulates approaches both from the political ecology and the socio-ecological systems and considers how important it is to understand the power relations emerging in community ecotourism contexts that, in turn, help to measure how this kind of tourism impacts the socio-ecological dynamics and the strategies by the peasant families who try to diversify their economies to made them sustainable.
\end{abstract}

Keywords: political ecology, socio-ecological systems, community ecotourism, peasant communities, Colombia, Amazonia, Guaviare.

\section{Introducción}

Desde la década de 1990, varias instituciones de cooperación internacional, agentes estatales y actores privados con injerencia en la Amazonia noroccidental c olombiana han propuesto los proyectos ecoturísticos entre comunidades rurales como una de las estrategias más viables para a) controlar la expansión de los cultivos de coca, b) legalizar a los campesinos que se dedican a su siembra y c) minimizar el impacto ambiental de las intervenciones antrópicas en los ecosistemas de transición entre la Orinoquia y la Amazonia (Montenegro, 20I4; Ortiz, 2016). Al vincularse a una estrategia de legalización y conservación, el Estado usa el ecoturismo como un dispositivo valioso 
para implementar estrategias sociales y participativas de conservación de áreas ecológicamente sensibles, enmarcadas en los paradigmas de la protección ambiental participativa, dominantes a escala global desde la década de 1980 (Dressler et al., 2010; Magome y Fabricius, 2004). En el actual escenario nacional de transición, luego de la firma de paz entre el Gobierno nacional y las FARC, el ecoturismo ha cobrado especial relevancia como estrategia de desarrollo rural en las zonas más afectadas por la violencia, priorizadas para la implementación del acuerdo de paz (Villamizar, 2017). Incluso al mismo tiempo que se desarrollaban las conversaciones de paz, el Gobierno nacional lanzó una política titulada Plan Sectorial de Turismo 20r4-2018, “Turismo para la construcción de paz”, en la que planteó el objetivo de posicionar al país como un destino "sostenible, sustentable y megadiverso" (Ministerio de Comercio, Industria y Turismo, 2016). En este contexto, el ecoturismo adquiere dimensiones geopolíticas, como ha sucedido en otras regiones de América Latina y del mundo, en la medida en que es frecuentemente utilizado como un dispositivo de gobierno de "territorios y gentes rebeldes" (Devine, 20I6, p. 2).

A pesar de los esfuerzos institucionales por promover el ecoturismo en poblaciones locales en zonas anteriormente dominadas por las FARC, las iniciativas ecoturísticas que se identifican en la región del Guaviare no son el resultado exclusivo del interés del Estado, del sector privado o de la implementación directa del acuerdo de paz; en efecto, en ese departamento se detectan algunas iniciativas lideradas por organizaciones comunitarias que buscan articular iniciativas ecoturísticas para gestionar los territorios que habitan y reivindicar, así, su derecho a seguir viviendo en áreas clasificadas como estratégicas por su biodiversidad. Esta singularidad permite explorar comparativamente qué sucede en términos de las dinámicas socioecológicas cuando el ecoturismo emerge como una iniciativa comunitaria.

Sin embargo, y a pesar de las diferencias entre las iniciativas ecoturísticas de tipo institucional, privado o comunitario, todas afectan la manera en que las comunidades rurales se relacionan con los ecosistemas que habitan. Este artículo analiza comparativamente las transformaciones socioecológicas en dos iniciativas de ecoturismo comunitario localizadas en dos veredas del eje fluvial Guayabero-Guaviare que hacen parte de la franja de transición de los biomas de la Orinoquia y la Amazonia, al suroriente de Colombia (figura I), un territorio estructurado por las dinámicas de la guerra y por la economía cocalera y hoy priorizado para la construcción de la paz territorial (Jaramillo, Castro-Herrera y Ortiz, 2018).

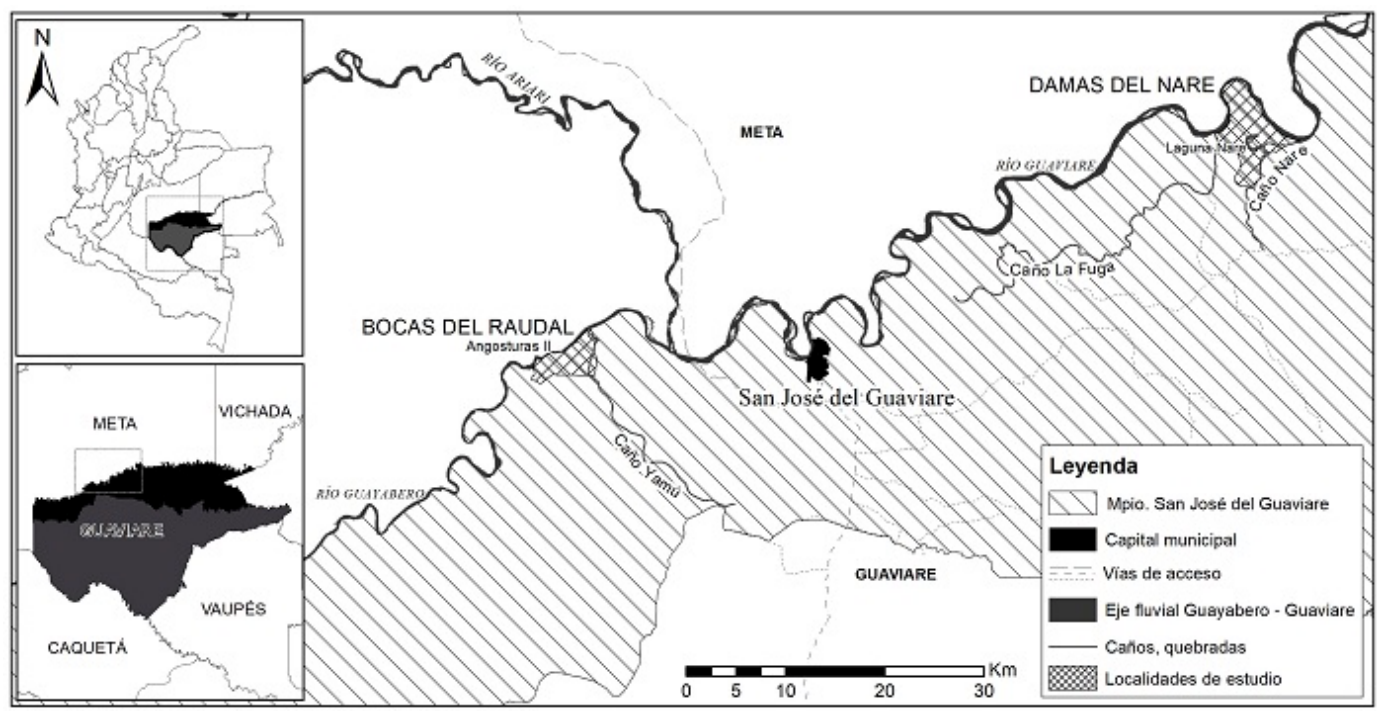

FIGURA 1

Área de estudio

Fuente: Juan Eduardo Ortega Martínez 
Nuestro análisis parte de la premisa de que el ecoturismo comunitario reconfigura las relaciones socioecológicas de forma multidimensional y compleja, transformando, por ejemplo, las relaciones de la gente con los sistemas productivos, las especies y los lugares. Al tiempo, el ecoturismo en estas dos localidades va tomando formas claramente divergentes cuando se trata de pensar su inserción como iniciativas comunitarias. Por esta razón, buscamos entender el ecoturismo dentro del marco de las transformaciones de los sistemas socioecológicos particulares en los que se desarrolla esa actividad. Estos sistemas los definimos como una densa red de interrelaciones sociohistóricas y ecológicas entre las comunidades y el entorno que habitan que generan un sistema caracterizado por ser complejo, autoorganizado y abierto al cambio y a la contingencia (Escalera y Ruiz, 20II; Folke et al., 2002; Holling, 200I). No obstante, los sistemas socioecológicos no están dados empíricamente, sino que son unidades delimitadas analíticamente para hacer viable un proceso investigativo (Becker, 20I2; Ostrom, 2009). De este modo, intentamos superar valoraciones reduccionistas que simplifican los efectos de las actividades turísticas como "buenas" o "malas" (Salazar, 2006), para comprenderlas en el marco de complejas y particulares relaciones socioecológicas analizadas desde una perspectiva sistémica, multidimensional y de poder. Para ello, desarrollamos un encuadre teórico-metodológico que articula enfoques de los sistemas socioecológicos y de la ecología política. Este segundo enfoque multidisciplinar plantea que los procesos socioecológicos emergen en el marco de complejas relaciones de poder por el control, el uso, la representación y el acceso a los recursos naturales (Biersack, 2006; Robbins, 2012) y que determinan, en alto grado, la desigualdad en la distribución de los costos y beneficios que generan actividades productivas como el turismo (Mostafanezhad, Norum, Shelton y Thompson-Carr, 2016). Además, la ecología política reivindica que la comprensión de esas relaciones debe abordarse desde una perspectiva multidimensional, especialmente en los niveles multiescalar, multitemporal, multisituado y multiagente (Del Cairo, MontenegroPerini y Vélez, 20I4).

Los enfoques de sistemas socioecológicos y la ecología política comparten el propósito de reconceptualizar los enfoques tradicionales que se interesan por la relación entre los seres humanos y la naturaleza desde perspectivas predominantemente materialistas o culturalistas (Fabinyi, Evans y Foale, 20I4; Turner, 20I4). Turner (20I4) argumenta que la ecología política y el enfoque de los sistemas socioecológicos se desarrollaron en paralelo y conectados y que comparten dos premisas centrales: primero, su preferencia por la comprensión del cambio -que en los estudios de sistemas socioecológicos suele vincularse con la noción de resiliencia- y de las transformaciones mediadas por la historia, y segundo, su reticencia a los modelos que simplifican la comprensión del equilibrio en la ecología y los estudios sociales (ver también Schoon y van der Leeuw, 2015). No obstante, acota Turner (20I4), a pesar de sus conexiones, ambos enfoques difieren ampliamente en sus abordajes: mientras que los sistemas socioecológicos son cercanos a la teoría de la economía política y los marcos de elección racional (McGinnis y Ostrom, 2014), la ecología política, por su parte, presta particular atención a la pregunta por el poder y las relaciones que este media (Biersack, 2006; Robbins, 20I2). Distintas investigaciones han profundizado en la comprensión de las diferencias entre los sistemas socioecológicos y la ecología política, como: el énfasis realista de los sistemas socioecológicos en contraposición al constructivista de la ecología política (Nightingale y Cote, 20ı2); la relevancia del abordaje del poder dentro de la ecología política y la ausencia de este en los sistemas socioecológicos (Boonstra, 2016; Bridge, McCarthy y Perreault, 2015; Fabinyi et al., 20I4; Nightingale y Cote, 2012; Robbins, 20I2); el tratamiento ligero que ciertas líneas de la ecología política suelen darles a las implicaciones ecológicas de las dinámicas políticas (Vayda y Walters, 1999), y el sesgo binarista y antropocéntrico presente en algunas de las perspectivas dominantes de la ecología política (Blaser y Escobar, 2016).

A pesar de las diferencias mencionadas, nuestro argumento parte de la complementariedad entre los dos enfoques, de manera que la integración de sus marcos de comprensión teórica y metodológica robustecen el entendimiento de los problemas de articulación ecológico-social, porque buscan operacionalizar el poder como 
una variable central para los sistemas socioecológicos (Boonstra, 20I6). Además, el vínculo entre ecología política y sistemas socioecológicos promueve estrategias de análisis relacional que ayudan a superar el sesgo binarista antes mencionado.

La comprensión de los impactos del ecoturismo en las dinámicas socioecológicas busca aportar a las discusiones contemporáneas que abordan esta actividad económica desde diferentes perspectivas disciplinarias. En efecto, en las últimas décadas se han planteado diversas discusiones sobre ecoturismo en general y el ecoturismo comunitario en particular, en campos tan diversos como la antropología, la ecología, la geografía y la ecología política (Burns, 1999; Dove, 2006; Mostafanezhad et al., 2016; Nepal, Saarinen y McLean-Purdon, 2016; West, 2006). Algunas de estas discusiones plantean el ecoturismo como una versión "verde" del turismo convencional con complejas y problemáticas convergencias con el neoliberalismo (Castree, 2008; Duffy, 2008; Montenegro, 20I4; Ojeda, 20I2). Este tipo de visiones sobre el ecoturismo son valiosas porque permiten comprender que el simple hecho de que una actividad sea considerada como "ecoturística", por realizarse en torno a atractivos principalmente ambientales y paisajísticos o en contextos rurales, no implica que se eliminen de tajo los efectos negativos que suelen asociarse a las dinámicas del turismo convencional.

Schulte (2003) señala que el turismo y el ecoturismo convencional son actividades económicas controladas por grandes empresas privadas, e incluso grandes corporaciones a nivel global, que persiguen un claro objetivo de generación de capital económico privado. Como se puede entrever en algunos análisis sobre iniciativas de ecoturismo de carácter privado (p. ej., Guilland y Ojeda, 2013; Ojeda, 20I2), es posible afirmar que este puede llegar incluso a ser más problemático que el turismo sin ribetes sostenibles, porque esconde y legitima relaciones de desigualdad tras una retórica verde y unos pretendidos objetivos empresariales de alcanzar la sostenibilidad ambiental, de fomentar el bienestar de las poblaciones que rodean los lugares donde se implementan estas iniciativas y de contribuir a la conservación de la naturaleza. De hecho, algunas aproximaciones críticas al estudio del ecoturismo señalan que, en los lineamientos para el desarrollo de esta actividad establecidos por organismos como la Organización Mundial del Turismo (OMT) y la Sociedad Internacional de Ecoturismo, se hace mucho énfasis en sus bondades al reivindicar, desde una perspectiva economicista, que existe una relación directamente proporcional entre el desarrollo del ecoturismo y el aumento de las posibilidades de fortalecer la conservación ambiental. Sin embargo, estas comprensiones no establecen consideraciones claras sobre las relaciones tensionantes entre oferta de servicios turísticos y degradación ambiental ni sobre el papel que deben cumplir las comunidades locales asentadas en áreas con potencial ecoturístico, las cuales suelen ser marginales, razón por la cual limitan su participación en los beneficios económicos derivados de esta actividad (Boley y Green, 2015; Nepal et al., 2016). Incluso, la OMT (1999, 2004) señala la necesidad de realizar investigaciones en los ecosistemas donde el ecoturismo se implementa, como un factor decisivo para el éxito de la actividad, con el propósito de asegurar que no se ponga en peligro la sostenibilidad a largo plazo de la actividad. Sin embargo, en estas perspectivas no se habla sobre la importancia que los ecosistemas regionales tienen para la supervivencia de comunidades locales que los habitan (Pérez, 2004).

En este sentido, es importante aclarar que el turismo y el ecoturismo no se diferencian en su esencia por ser actividades económicas con réditos desigualmente distribuidos, sino por el tipo de atractivos que las caracterizan. Por esta razón, es posible que algunas de las líneas dominantes en la comprensión de los procesos asociados al ecoturismo tiendan a simplificar sus efectos como "buenos" o "malos" (Salazar, 2006, pp. II6-II7), al igual que se hace con el turismo en general (Schulte, 2003). Sin embargo, en contraposición a este tipo de análisis, en nuestro argumento comprendemos el ecoturismo como una actividad contextualmente dependiente de las particularidades socioecológicas y sociohistóricas donde se inserta (Cawley y Conway, 20I6). Además, señalamos que existe un tipo de ecoturismo que denominamos ecoturismo comunitario, el cual resulta de la iniciativa de comunidades de base (Stronza, 2008) en su búsqueda por ofrecer servicios ecoturísticos bajo premisas que 
responden a expectativas sociales con respecto a sus territorios y con las que procuran, así, generar réditos económicos que puedan redistribuirse de manera más equitativa y efectiva entre sus miembros.

Como se verá en el desarrollo del artículo, los dos casos analizados en nuestra investigación son considerados como de ecoturismo comunitario porque, a pesar de sus diferencias y diferentes grados de cohesión comunitaria, han sido liderados y diseñados desde sus inicios por organizaciones comunitarias con la intencionalidad de beneficiar a los habitantes de las veredas, aunque en su implementación se hayan podido incorporar en diversa medida procesos que modifican de algún modo sus propósitos originales. No se trata, sin embargo, de iniciativas que necesariamente hayan redundado en la consolidación de lazos comunitarios, como ya analizaremos, hecho que permite argumentar que el ecoturismo comunitario es una actividad heterogénea cuyas características y formas de consolidación están determinadas por los factores ecológicos y sociohistóricos que singularizan el contexto donde se implemente. En los casos que tratamos en este artículo, las características que asumen las iniciativas de turismo comunitario son principalmente el resultado de la impronta diferenciada que ha dejado el conflicto armado en las dinámicas sociales y organizativas de las dos veredas: Bocas del Raudal y Damas del Nare.

\section{Metodología}

\section{Área de estudio}

Los sistemas socioecológicos analizados en las dos veredas, situadas en el municipio de San José del Guaviare (Colombia), se caracterizan por ser parte de ecosistemas de transición entre los biomas orinocense y amazonense. Están localizados en el eje fluvial Guayabero-Guaviare y comparten características ecológicas como una matriz de bosque húmedo intermediada por zonas de producción, ecotonos y ecosistemas de sabana. Sin embargo, tienen diferencias sensibles en cuanto a las condiciones biofísicas y geomorfológicas, ya que la vereda Bocas del Raudal tiene geoformas propias de la serranía de La Lindosa, en las que convergen afloramientos rocosos de tres unidades geológicas diferentes (Cárdenas, Castaño, Zubieta y Jaramillo, 2008), frente a la vereda Damas del Nare, que, por su parte, está integrada por los planos de inundación del río Guaviare, en donde predominan sistemas lagunares y bosques inundables (várzeas).

Los sistemas socioecológicos de las dos veredas se caracterizan por tres particularidades ecológicas funcionales al ecoturismo: los afloramientos rocosos precámbricos de la serranía de La Lindosa, cuerpos de agua relacionados con condiciones geomorfológicas (laguna El Espejo, en Damas del Nare, y el Raudal Angosturas II, en Bocas del Raudal) y una biodiversidad propia de los ecosistemas de transición orinoco-amazonenses, que resultan llamativos a los visitantes. Además, las veredas comparten procesos sociohistóricos vinculados a las estrategias de colonización campesina y a las economías extractivas y productivas ilegales (como las de la marihuana y la coca), que dominaron las corrientes de poblamiento desde mediados del siglo XX (Acosta, 1993; Molano, 1987). También comparten dinámicas propias del conflicto armado que han tenido distintas implicaciones para los sistemas productivos locales: desde las regulaciones económicas por parte de actores armados, que imponen qué sembrar y en qué proporciones, hasta el abandono de fincas como resultado de desplazamientos forzados, pasando por afectaciones en la calidad de los suelos y las fuentes de agua y por el daño a los cultivos producto de las aspersiones aéreas con glifosato (Dávalos, Bejarano y Correa, 2008; Oficina en Washington para Asuntos Latinoamericanos e Instituto de Estudios para el Desarrollo y la Paz, 2009). 
En la actualidad, la implementación del acuerdo de paz entre el Gobierno y las FARC sitúa una nueva coyuntura histórica que viene ocasionando algunos cambios en las localidades de estudio. Esto, en particular, obedece al cese de las confrontaciones armadas, a la concentración de las FARC en los dos espacios territoriales de capacitación y reincorporación (ETCR) del departamento del Guaviare y la implementación del llamado acuerdo agrario que agrupan los puntos i y 4 del acuerdo (Fajardo y Salgado, 20I7). De hecho, el municipio de San José del Guaviare está priorizado para la implementación de planes de desarrollo con enfoque territorial (Decreto 893 de 2017 [Ministerio de Agricultura y Desarrollo Rural, 28 de mayo de 2017]) y del Programa Nacional Integral de Sustitución de Cultivos de Uso Ilícito (PNIS) (Decreto 896 de 2017 [Presidencia de la República de Colombia, 29 de mayo de 2017]). A pesar de la potencialidad que representan estos decretos para tramitar las problemáticas rurales y ambientales del departamento, las trabas en su reglamentación, las discrepancias del Gobierno nacional y la FARC en la Comisión de Seguimiento, Impulso, Verificación e Implementación (Csivi) y el déficit de recursos fiscales y capacidad institucional del Estado para materializar el acuerdo de manera efectiva (Observatorio de Seguimiento a la Implementación del Acuerdo de Paz, 2017) han postergado su implementación y, en la misma medida, han frenado la posibilidad de incidir en la transformación de las causas estructurales del conflicto a nivel territorial y en los procesos que han intensificado la degradación de muchos de los ecosistemas regionales por intervenciones como la deforestación y las quemas indiscriminadas.

A estas dificultades de la implementación del acuerdo de paz se suma la reconfiguración de grupos armados residuales en el municipio de San José del Guaviare, segregados de estructuras como los frentes I y VII de las FARC, y la entrada de nuevos actores posdesmovilización de las AUC (Defensoría del Pueblo, 20I7). Las eventuales confrontaciones armadas entre estos actores y el Ejército Nacional podrían activar nuevos ciclos de violencia que entorpecerían la formalización y consolidación de algunas de las iniciativas de ecoturismo comunitario que se vienen gestando en el departamento.

\section{Discusión teórico-metodológica}

Las particularidades sociohistóricas y ecológicas que establecimos analíticamente para delimitar los sistemas socioecológicos de referencia (Becker, 20I2) están asociadas a las dinámicas del ecoturismo comunitario a escala local. La integración de los marcos analíticos de los sistemas socioecológicos y la ecología política en nuestra investigación tuvo como propósito comprender dos contextos socioecológicos complejos, adaptativos y diversos, cuyo análisis exige una reducción de su complejidad (Capra y Cempau, 1998). El marco analítico de los sistemas socioecológicos permitió abstraer y definir las variables específicas que se usaron para establecer los contornos del sistema y que son imprescindibles para priorizar algunos patrones de relaciones en las dinámicas sociales, ecológicas y productivas asociadas a la actividad ecoturística de cada vereda. La perspectiva de ecología política, por su parte, potenció el análisis multidimensional de las transformaciones mediadas por las dinámicas de poder que emergen e intervienen en la configuración de tales relaciones.

El paso crucial en este proceso fue el establecimiento de criterios específicos de delimitación de los sistemas socioecológicos (Ostrom, 1990) para comprender sus patrones y relaciones específicas (Becker, 20I2). Este proceso partió del reconocimiento de la porosidad y el dinamismo de sus límites, por cuenta de la variabilidad en las escalas espaciotemporales que contienen. Tal reconocimiento disuelve las concepciones de los límites de los sistemas socioecológicos como discretos y constantes (Fabinyi et al., 20I4), de manera que los límites son analíticos en lugar de autoevidentes, espaciales y funcionales y permiten acotar la mirada sobre un conjunto de elementos y relaciones a describir. 
En nuestro caso de estudio comparativo, la estrategia para definir los límites de los sistemas pasó por el establecimiento de cuatro relaciones centrales vinculadas con la actividad ecoturística: a) gente-lugares, es decir, el conjunto de transformaciones y representaciones sobre los espacios en que transcurren actividades ecoturísticas de carácter comunitario; b) gente-especies, que implica los usos y las resignificaciones de plantas y animales que se aprovechan como atractivo ecoturístico; c) gente-sistemas productivos, que describe las transformaciones del trabajo, la producción y la comercialización de sus productos con la incorporación o potenciación de la economía de servicios ecoturísticos, y d) gente-ecoturismo, que implica las prácticas y representaciones asociadas a esta actividad y la organización social y los agentes vinculados. Esta última relación actuó como eje transversal a través del cual se analizaron las transformaciones que han operado en las otras tres relaciones priorizadas.

En cada relación, identificamos elementos sociales y ecológicos desde una perspectiva que reivindica su condición híbrida (Becker, 2012; Latour, 2008). Con esto, se destacaron el carácter relacional de esos elementos y los agregados de particularidades ecológicas y sociohistóricas que configuran, reconociendo que estas divisiones se establecen intencionalmente en el plano analítico para estudiar el sistema (Becker, 20I2), sin desconocer que esa disección analítica es puramente instrumental. Entendemos las particularidades ecológicas como el conjunto de rasgos estructurales y funcionales de un ecosistema que lo configuran como unidad y que permiten diferenciar sus relaciones internas de aquellas que suceden en su entorno, separándolo de otros ecosistemas. Las particularidades sociohistóricas, por otro lado, describen el conjunto de características que configuran las relaciones sociales de un grupo social específico o comunidad local; en él tienen lugar instituciones, normas, representaciones, trayectorias históricas singulares y relaciones de poder, entre otros rasgos. La composición de ambos conjuntos establece las características definitorias de los sistemas socioecológicos y establece sus condiciones de posibilidad.

La indagación por las cuatro relaciones y sus particularidades ecológicas y sociohistóricas se hizo con metodologías propias de las ciencias sociales y ambientales que se pusieron permanentemente en diálogo con la intencionalidad de tejer puentes interdisciplinarios (Binder, Hinkel, Bots y Pahl-Wostl, 20I3; Moran, 20II; Newell et al., 2005). La tabla i contiene una síntesis de las metodologías y técnicas que se utilizaron durante la fase de campo de la investigación.

TABLA 1

RELACIONES SOCIOECOLÓGICAS Y ESTRATEGIAS DE INVESTIGACIÓN

\begin{tabular}{|c|c|c|c|}
\hline Relaciones socioecológicas & $\begin{array}{c}\text { Relaciones } \\
\text { asociadas }\end{array}$ & Técnicas de recolección de información & $\begin{array}{c}\begin{array}{c}\text { Estrategia de } \\
\text { sistematización }\end{array} \\
\text { sistate }\end{array}$ \\
\hline \multirow{6}{*}{ Gente-lugares (GL) } & Lugares significativos y orientados al uso del turismo & Cartografia social (Torres, Rátiva y Varela, 2012 & Digitalización \\
\hline & \multirow{4}{*}{ Estado general de los ecosistemas } & \multirow{2}{*}{$\begin{array}{l}\text { Recorridos guiados por sendas (Aguilar-Garavito y } \\
\text { Ramirez, 2015; Peres, 1999) }\end{array}$} & Georreferenciación \\
\hline & & & Conteos e inventarios \\
\hline & & \multirow{2}{*}{$\begin{array}{l}\text { Fotointerpretación y } \\
\text { levantamiento de mapas de cobertura (Chuvieco, 1996; } \\
\text { Melo y Camacho, 2005) }\end{array}$} & Arc-Gis \\
\hline & & & $\begin{array}{l}\text { Análisis multitemporal de } \\
\text { coberturas }\end{array}$ \\
\hline & Colonización y poblamiento & Grupos focales (Kitzinger, 1995) & Línea de tiempo \\
\hline \multirow{4}{*}{ Gente-especies (GE) } & \multirow{2}{*}{ Prácticas y representaciones alrededor de la naturaleza } & Grupos focales (Kitzinger, 1995) & $\begin{array}{l}\text { Matriz histórica de } \\
\text { evaluación de recursos }\end{array}$ \\
\hline & & Observación participante (Restrepo, 2016) & Diario de campo \\
\hline & Regímenes de comportamiento animal & Grupos focales (Kitzinger, 1995) & Transcripción selectiva \\
\hline & Especies significativas orientadas al uso turístico & $\begin{array}{l}\text { Muestreos participativos de especies dirigidos/aleatorios } \\
\text { (Aguilar-Garavito y Ramirez, 2015; Trinh, Nguyen y } \\
\text { Rastall, 2016) }\end{array}$ & $\begin{array}{l}\text { Análisis comparativo de } \\
\text { especies } \\
\text { potenciales/percibidas }\end{array}$ \\
\hline \multirow{4}{*}{ Gente-sistemas productivos (GSP) } & Uso y propiedad del suelo & \multirow{3}{*}{$\begin{array}{l}\text { Encuesta de caracterización socioeconómica (Álvarez } \\
\text { Uribe, Mancilla López y Cortes Torres, 2007) }\end{array}$} & \multirow{3}{*}{ Tabulación de encuesta } \\
\hline & Gasto y generación de ingresos & & \\
\hline & Comercialización & & \\
\hline & Cambios en las economias y formas de producción & Entrevistas a profundidad (Guber, 2001) & Transcripción selectiva \\
\hline \multirow{2}{*}{ Gente-ecoturismo (GET) } & Representaciones sobre el turismo & Entrevistas a profundidad (Guber, 2001) & Transcripción selectiva \\
\hline & Organización social y agentes asociados al turismo & Red de actores (Guedes, 2004) & Mapa de actores \\
\hline
\end{tabular}


Teniendo en cuenta las críticas realizadas al enfoque de sistemas socioecológicos en relación con la ausencia de una lectura sobre dimensiones que imbrican múltiples escalas y, en particular, con la marginalidad que tienen las relaciones de poder en este enfoque (Boonstra, 20I6; Fabinyi et al., 20I4; Nightingale y Cote, 2012), nutrimos teóricamente el análisis de los datos recopilados sobre las cuatro relaciones socioecológicas priorizadas incorporando las dimensiones multitemporal, multiescalar, multisituada y multiagente, relevantes para la perspectiva analítica de la ecología política (Del Cairo et al., 20I4). Estas dimensiones refieren a las condiciones de transformación histórica de las relaciones y de los elementos de los sistemas socioecológicos (dimensión multitemporal), a las diferentes escalas (local, regional, nacional e internacional) en las que suceden las relaciones socioecológicas del sistema y a su articulación de manera interdependiente (dimensión multiescalar), a los diferentes lugares donde se desarrollan las interacciones entre partes del sistema o entre sistemas de otras localidades que se vinculan a través de análisis comparativos (dimensión multisituada) y a los múltiples agentes que inciden en las condiciones, las posibilidades de existencia y el funcionamiento del sistema (dimensión multiagente).

Al enmarcar el análisis de las relaciones priorizadas dentro de los sistemas socioecológicos en una aproximación que aborda las múltiples dimensiones que propone la ecología política, se evita el riesgo de perder el abordaje crítico sobre las relaciones históricas y de poder que están inmersas en ellos, de manera que estos sistemas dejan de entenderse como entidades estáticas y funcionales.

\section{Resultados}

El estudio comparativo entre los dos sistemas socioecológicos estudiados evidencia una serie de transformaciones en las relaciones gente-ecoturismo, gente-sistemas productivos, gente-lugares y gente-especies. La exposición comparativa de las transformaciones de estas relaciones se presenta desde una perspectiva integradora entre las dimensiones sociohistóricas y ecológicas.

El ecoturismo en ambas veredas tiene condiciones y orígenes diferentes, que, siguiendo el análisis multitemporal, responden a la construcción histórica de relaciones socioecológicas que se reconfiguran en sucesivas coyunturas (Wolf, 2006). Cabe precisar que, en el caso de Bocas del Raudal, sobre las fases iniciales de esta actividad, que tuvieron lugar hace varias décadas, no hablamos de ecoturismo porque en ese momento no se promovió la visita al lugar para explorar los atractivos naturales y paisajísticos. En efecto, en esta vereda, el turismo comenzó a principios de la década de 1970 a través de visitantes interesados en la pesca y la cacería, como explicaremos más adelante, y posteriormente se fue consolidando alrededor de la oferta paisajística del Raudal Angosturas II, en el río Guayabero, y de las pinturas rupestres ubicadas sobre las formaciones rocosas precámbricas que rodean el lugar. Desde ese tiempo, las actividades turísticas, y luego ecoturísticas, experimentaron varios auges y crisis provocadas por las dinámicas del conflicto armado y por la movilización social campesina. En Damas del Nare, en cambio, el ecoturismo no tiene más de siete años de haber iniciado y gira principalmente en torno al avistamiento de delfines rosados (Inia geoffrensis humboldtiana) en la laguna El Espejo. Esta actividad es el resultado de la promoción de agentes del Gobierno departamental que impulsaron la creación de empresas prestadoras de servicios turísticos en áreas rurales. Las capacitaciones y los apoyos institucionales en esta vereda ayudaron a formalizar dos empresas de ecoturismo: una que se planeó inicialmente con un carácter cooperativo, pero que hoy está en manos de un solo núcleo familiar, y otra de carácter privado derivada de la separación de uno de los integrantes de la primera. En Bocas del Raudal, en cambio, las iniciativas de turismo y ecoturismo surgieron antes de la llegada de los agentes estatales que promueven estas actividades, los cuales solo lograron 
ingresar a la zona en años muy recientes, cuando se dio el desescalamiento del conflicto armado en la región como resultado de los diálogos de paz entre el Gobierno y las FARC.

La comunidad de Bocas del Raudal identifica los orígenes de esta actividad en lo que denominan el "turismo extractivo" de la década de 1970, que consistió principalmente en visitas de grupos del interior del país atraídos por la exuberancia de los bienes comunes pesqueros y silvestres de la zona. Estos grupos permanecían en la vereda cortos periodos de tiempo y le pagaban a la población local los servicios de hospedaje, alimentación y guianza, principalmente para desarrollar actividades de pesca y cacería. Esta primera ola de turismo acabó por cuenta de las dinámicas del conflicto, con la llegada de las FARC a la región a principios de la década de i980, cuando establecieron normas ambientales y, entre ellas, les prohibieron la pesca y la caza a personas externas a la comunidad. Posteriormente, hubo dos intentos para promover el ecoturismo con características marcadamente comunitarias y autónomas. El primero de ellos ocurrió a finales de la década de 1990 y fue liderado por dos personas adscritas a la junta de acción comunal (JAC) y a la Unión Patriótica (UP) (comunicación personal, Bocas del Raudal, 2017). El segundo ocurrió hacia finales de la década de 2010 y estuvo bajo el liderazgo de un miembro de la comunidad que se encargó de gestionar el ecoturismo. Estos impulsos terminaron cuando las FARC asesinaron al líder tras acusarlo de ser informante del Ejército Nacional. Desde entonces, las FARC prohibieron tajantemente cualquier tipo de turismo en la vereda, argumentando que el Ejército podría infiltrar informantes en los grupos de visitantes (comunicación personal, Bocas del Raudal, 2017).

Esta prohibición, y en general la influencia de la guerrilla, evitó que instituciones como el Servicio Nacional de Aprendizaje (SENA), a cargo de la formación de la población local en temas de prestación de servicios turísticos, ingresaran a la vereda a inicios de la década de 2010 en el marco de la política "Paraísos turísticos por descubrir”, que se venía implementando. Esto sí ocurrió en Damas del Nare, donde el SENA y otras instituciones y organizaciones no gubernamentales, apoyadas con recursos de la Unión Europea y la Corporación para el Desarrollo Sostenible del Norte y Oriente Amazónico (CDA), llevaron a cabo actividades desde el enfoque institucional orientadas a crear y formalizar empresas de turismo en zonas rurales. Como resultado de la presencia institucional, diferenciada entre las veredas por cuenta de las dinámicas del conflicto, en Bocas del Raudal la primera organización externa que entró a fomentar formalmente el ecoturismo fue Ecoamem, una cooperativa de ecoturismo comunitario de escala regional adscrita a la Corporación por la Defensa Ambiental y el Desarrollo Sostenible en el AMEM (Corpoamem), que es una organización de segundo nivel conformada por las organizaciones campesinas, indígenas y afrodescendientes que se encuentran en el Área de Manejo Especial de La Macarena (AMEM). En el caso de Damas del Nare, las instituciones que se encargaron de promover y formalizar las iniciativas ecoturísticas fueron entidades como el SENA y la Secretaría Departamental de Cultura y Turismo.

Estas particularidades en el surgimiento del turismo, en un primer momento, y del ecoturismo, en años recientes, son la condición de posibilidad para la organización actual de las actividades de ecoturismo comunitario en las veredas. Esto denota la importancia de articular las múltiples dimensiones de la ecología política con la perspectiva de análisis sistémica para la comprensión densa de los patrones de relación actuales; de otra manera, la investigación solamente describiría el estado actual de los patrones de relación y no explicaría necesariamente su origen.

En términos generales, los procesos reseñados resultaron en la implementación de dos formas sensiblemente diferentes de ecoturismo comunitario con grados diferentes de trabajo colectivo: el caso de Bocas del Raudal se asoció con estrategias colectivizadas, propias de una tradición de movilización social campesina, orientadas a alcanzar objetivos sociales, económicos y ecológicos comunales, mediados y regulados por la JAC, y el caso de Damas del Nare se vinculó a visiones institucionales del ecoturismo de múltiples escalas, bajo los principios de formalización, regulación y planes de negocios orientados a fortalecer unidades familiares en el marco de lineamientos nacionales de gestión del turismo convergentes con acuerdos internacionales en la materia, particularmente promovidos por la OMT. 
Una expresión concreta de las diferencias entre esas concepciones de ecoturismo comunitario tiene que ver, precisamente, con el papel que desempeñan las JAC en las actividades de cada vereda. Las JAC son instituciones comunitarias que lideran acuerdos para gestionar los recursos a los que tiene acceso la comunidad y obtener de ellos beneficios colectivos de forma duradera; tramitar los conflictos sociales que puedan surgir por su acceso, uso y control, y evitar la degradación ambiental a partir de normas vinculantes y descentralizadas (Jaramillo, CastroHerrera, Zambrano y Ortiz, 20ı8; Ostrom, 2009). En el caso de Bocas del Raudal, existe un acuerdo comunitario según el cual cada turista paga una contribución a la JAC. Además, la JAC supervisa la rotación de turnos entre las personas que prestan servicios turísticos (alimentación, guianza, alojamiento y transporte, principalmente) y regula la estandarización de precios. Esas estrategias promueven una distribución más equitativa de los ingresos derivados del ecoturismo y, además, intentan asegurar la rotación de la prestación de servicios entre distintas personas para que se pueda beneficiar un mayor número de familias de la vereda. Aunque no está exento de conflictos y fisuras, se trata de un sistema que prioriza el cumplimiento de objetivos comunitarios por encima de objetivos particulares, ya que evita la concentración de actividades en una misma persona o familia, al tiempo que crea conciencia sobre la importancia de rotar coordinadamente la prestación de servicios y beneficiar, de este modo, a más personas de la comunidad.

En Damas del Nare, el enfoque del ecoturismo ha estado permeado por actividades e iniciativas de instituciones oficiales y algunas oenegés, y es frecuente que los prestadores de servicios enfaticen el carácter "comunitario" de su actividad ecoturística. Sin embargo, entre este caso y el de Bocas del Raudal se identifican claras diferencias en las estrategias para comunalizar las responsabilidades, las actividades y los ingresos derivados de esta actividad. Por ejemplo, en Damas del Nare, los turistas no realizan ningún aporte económico a la JAC, hecho que ha generado tensiones entre las iniciativas ecoturísticas y esta institución comunitaria. Allí, además, se evidencian relaciones de poder desiguales entre los distintos actores involucrados en el ecoturismo de la vereda que se expresan, primero, en la falta de coordinación para ofertar servicios y, segundo, en la ausencia de mecanismos consensuados para asegurar la redistribución de los réditos del ecoturismo y para manejar el acceso y mantenimiento de los atractivos de la vereda. También se ha fomentado una lógica de libre competencia entre las diferentes iniciativas ecoturísticas que se han ido consolidando en la vereda. Como resultado, cada una de ellas intenta acceder prioritariamente a los lugares turísticos y ajustar los precios para ganarse el favor de los operadores turísticos de San José del Guaviare. Por otro lado, se registran tensiones sociales ocasionadas por la apropiación privada del trabajo comunitario en el marco de los mandatos de la JAC; estos mandatos son una institución de trabajo comunitario de escala veredal promovida por las JAC para construir o mejorar infraestructura para el beneficio de la comunidad. Las tensiones en torno a los mandatos se relacionan con lo que algunos asociados a la junta consideran un aprovechamiento por parte de las pocas familias de la vereda que obtienen recursos económicos al movilizar turistas por las trochas, puentes y caños, que son periódicamente mantenidos con el trabajo colectivo de toda la vereda para asegurar la movilidad de sus habitantes. Sin embargo, consideramos que en Damas del Nare también es posible señalar la actividad como ecoturismo comunitario, pues su origen fue cooperativo y, a pesar de las profundas conflictividades internas, la JAC vigila en cierta medida el funcionamiento de las iniciativas como autoridad local competente y persiste en su intento de identificar e implementar estrategias para robustecer los lazos comunitarios que se pueden crear en torno al ecoturismo.

La transformación de los sistemas socioecológicos en relación con el ecoturismo tiene que ver con la relación gente-sistemas productivos y sus transformaciones a lo largo del tiempo. Para analizar esta relación, resulta sustancial complementar la perspectiva sistémica con una mirada multidimensional de la ecología política. En efecto, las perspectivas multiagente, multiescalar y multitemporal permiten entender la manera en que las actividades económicas de los habitantes locales se han estructurado y transformado en diferentes momentos 
históricos, respondiendo a diferentes condiciones económicas de escala regional y nacional y a diferentes esquemas moralizantes que los discursos institucionales elaboran y despliegan sobre las prácticas productivas de las familias campesinas que habitan en esta región.

En términos generales, la literatura sobre el proceso de colonización del Guaviare identifica diferentes momentos en los que los sistemas de producción campesina de la región se han articulado a diferentes bonanzas extractivas: el caucho, las pieles de animales silvestres, la marihuana y posteriormente la economía de la coca (Acosta, 1993; Molano, 1987). Estas economías extractivas han generado a lo largo del tiempo evidentes presiones sobre los ecosistemas, que han devenido en formas institucionales de entenderlas y en diferentes políticas públicas que han procurado disminuir los impactos, al tiempo que buscan proponer estrategias económicas legales para las poblaciones.

Por ejemplo, agentes institucionales de las escalas regional y nacional clasifican desde hace un tiempo las diversas prácticas de los campesinos como "buenas" o "malas", "legales" o "ilegales" (Montenegro, 20r4). Algunas de esas prácticas tienen que ver con el establecimiento de sistemas agroforestales, economías de servicios, la cacería o la siembra de coca. En consecuencia, agentes institucionales vinculados a instituciones como la CDA y la Secretaría de Cultura y Turismo de la Gobernación del Guaviare han incidido desde la década de 1990 en que el ecoturismo emerja en toda la región como una actividad económica legal y legítima que se orienta a complementar y, en el mejor de los casos, a reemplazar actividades para reducir la presión de los sistemas productivos campesinos sobre los bienes comunes naturales de la región.

En efecto, este viraje institucional de promoción del ecoturismo ha generado ciertas transformaciones, por ejemplo, en las expectativas que los habitantes tienen sobre sus fuentes de ingresos. Esto se hace evidente en el hecho de que parte de las familias de ambas veredas no perciben ingresos económicos por cuenta del ecoturismo (un $27 \%$ en Damas del Nare y un 31\% en Bocas del Raudal), ya que se dedican exclusivamente a la agricultura de autoabastecimiento $u$ otras actividades agropecuarias. Sin embargo, la mayoría de los habitantes de ambas veredas encuentran hoy en el ecoturismo una actividad que desean desarrollar en el futuro. En el caso específico de Bocas del Raudal, el 75\% de sus habitantes espera recibir ingresos del ecoturismo en los próximos años. A raíz de estas expectativas, ha aumentado la preocupación de algunas familias campesinas por generar productos en sus fincas que puedan llegar a ser consumidos por los turistas o, también, por adecuar espacios de sus casas, de sus fincas y de la vereda para hospedar y atender a los visitantes. Esto ha traído algunas transformaciones de los sistemas productivos locales, los cuales se han ajustado paulatinamente a las demandas que implican las actividades de ecoturismo comunitario. Algo similar ocurre en Damas del Nare, donde, incluso, algunas familias inscritas en el PNIS contemplan invertir parte del dinero de proyectos productivos que otorga este programa en el desarrollo de infraestructura necesaria para las actividades ecoturísticas.

Las familias de las localidades de estudio que sí derivan ingresos de las actividades ecoturísticas los complementan con otras actividades productivas. En Damas del Nare, el ecoturismo se vincula a un tipo de economía campesina basada en la producción agrícola de pancoger, caza y pesca y, cada vez menos, en la siembra y el procesamiento de cultivos de coca. En Bocas del Raudal, el ecoturismo se engrana con la economía de servicios en el caserío, asociada al tránsito de viajeros regionales por el río Guayabero -cuya economía se mueve principalmente alrededor de la coca-, y, en algunos casos, con la pesca y el jornaleo. Desde la década de i980, este lugar se convirtió en un punto de prestación de servicios para los habituales viajeros que tenían que parar obligatoriamente allí para pasar a pie el raudal y evitar el riesgo de un naufragio. Esto definió una vocación de prestación de servicios en la vereda que facilitó la emergencia del ecoturismo años después. Sin embargo, en esta vereda se identifica una clara diferencia entre las familias que viven en el núcleo del caserío, que suelen vincularse a la provisión de servicios de alimentación, alojamiento, guianza y transporte para los turistas o las personas en tránsito por el río Guayabero, y las familias que se localizan fuera del caserío y que poco se han vinculado a estas actividades. 
A grandes rasgos, los hogares campesinos que se han articulado al ecoturismo lo han hecho bajo el supuesto de que esta actividad es congruente con la conservación ambiental, según los discursos que se empezaron a posicionar en décadas recientes desde dos lógicas diametralmente opuestas: las institucionales, asociadas a los imperativos nacionales y globales de conservación ambiental, y las insurgentes, vinculadas a los imperativos locales de mantener ciertas áreas "conservadas" por su incidencia en la geopolítica del conflicto armado. Ambas lógicas generaron formas concretas de regular la vida campesina que repercutieron en la transformación de los sistemas productivos locales. En Damas del Nare, por ejemplo, las familias que se han articulado a proyectos ecoturísticos han modificado la distribución espacial de los cultivos de sus fincas para facilitar la adecuación de senderos y terrenos limpios para zonas de camping. En ambas localidades está emergiendo una economía de servicios asociada al ecoturismo, y, con ella, algunos habitantes de las veredas han comenzado a resignificar actividades productivas como el cultivo y procesamiento de hoja de coca, ya que las ven ahora como la expresión de una economía ilícita y de alto impacto ambiental que riñe con los propósitos de un ecoturismo comunitario y de conservación de la naturaleza que buscan proteger los ecosistemas y beneficiar a la población. En los sistemas productivos de algunas fincas de Damas del Nare, se observa cómo en años recientes se han revalorado parches de bosques, lagunas y caños como sitios que deben ser conservados, hecho que también ha generado conflictos con otros actores regionales, como algunos indígenas asentados en las inmediaciones de la vereda que acceden a recursos como la pesca y la caza y que los campesinos empiezan a ver como una "molestia" (y que por momentos algunos conciben como una "amenaza") porque degradan los ecosistemas que atraen a los turistas.

Con el posicionamiento del ecoturismo en las localidades, también se ha empezado a modificar la relación de la gente con los lugares a los que les atribuyen un potencial paisajístico. De allí que los habitantes de Damas del Nare están resignificando lugares como la laguna El Espejo, pues la empiezan a ver como un lugar que debe ser conservado en virtud de las especies que la habitan, particularmente de las toninas, que pasan prácticamente todo el año en sus aguas. Para ello, han impulsado nuevos acuerdos y normas para que actores veredales y regionales puedan acceder a la laguna y a sus recursos de una manera menos intensiva, que no afecte el bienestar de las toninas ni amenace su permanencia en ella. Algo similar sucede en Bocas del Raudal, donde la comunidad comienza a revalorizar y resignificar las pinturas rupestres, los afloramientos rocosos y el raudal mismo, porque representan importantes atractivos con los cuales quieren posicionar la vereda como destino ecoturístico. No obstante, es muy probable que la revalorización específica de las pinturas rupestres del raudal del Guayabero se dinamice de maneras aún no previsibles como resultado de la declaratoria de esa zona como área arqueológica protegida del país en mayo de 2018 .

La resignificación también ha operado en el caso de algunos lugares, por el significado histórico que encierran y porque empiezan a ser visitados por y narrados a los turistas en los ejercicios de guianza como una forma de darles profundidad temporal a las veredas y nuevos sentidos a los procesos históricos regionales. Este es el caso de lugares de memoria de la colonización, el conflicto armado y las bonanzas cocaleras. En este sentido, la guianza que hacen en el marco del ecoturismo comunitario les ha permitido a los pobladores posicionar sus historias y memorias ante personas foráneas y, del mismo modo, dialogar con miradas externas sobre sus territorios y los lugares que consideran significativos.

El surgimiento del ecoturismo también ha implicado transformaciones en la relación con varias especies vegetales y animales de estas localidades, las cuales empiezan a ser revaloradas de formas particulares por su papel dentro de la actividad ecoturística. En las dos veredas, la situación de algunos animales como la lapa (Cuniculus paca), el cafuche (Tayassu pecari) y el chigüiro (Hydrochoerus hydrochaeris), que antes tenían un valor principalmente alimenticio, ha cambiado, pues ahora son resignificados como animales exóticos que pueden ser avistados por los turistas. Algo similar ocurre con las aves, que anteriormente se valoraban porque sus comportamientos constituyen indicadores de ciclos climáticos importantes para la agricultura regional y hoy 
también adquieren un valor como atractivo, especialmente para aquellos visitantes que se especializan en la observación de aves; en efecto, el avistamiento de aves se plantea en las dos localidades como uno de los mayores potenciales ecoturísticos debido a la alta diversidad de especies que albergan. En los ejercicios de muestreo dirigidos/aleatorios de caracterización de avifauna que realizamos durante esta investigación, se logró identificar, en época de invierno (junio-julio), un inventario de 9r especies en la vereda Bocas del Raudal. En Damas del Nare, por su parte, se registraron 75 especies de aves.

Las especies maderables también han sido resignificadas con la misma lógica de las especies animales, ya que antes su importancia principal giraba en torno a su utilidad para la construcción de casas, cercas y canoas y ahora representan un aspecto importante del paisaje que los habitantes locales consideran funcional al ecoturismo. Incluso, están diseñando senderos para avistar grandes ejemplares de caobas, cachicamos y otros árboles de gran talla, que pueden cautivar la atención de los visitantes.

Es importante señalar que las nuevas valoraciones de los pobladores sobre algunas especies, derivadas del potencial ecoturístico que identifican en ellas, dinamizan las formas previas de conceptualizarlas, pero no las reemplazan. En efecto, las personas de las veredas siguen cazando, pescando y usando especies maderables, guiadas por los acuerdos y sentidos previos a las iniciativas de ecoturismo; sin embargo, las nuevas valoraciones de las que son objeto estas especies y lugares en función del ecoturismo han provocado el establecimiento de nuevos acuerdos comunitarios de regulación sobre el uso y acceso a estos recursos desde sus sistemas de gobernanza (Ostrom, 2009). Estos nuevos acuerdos complementan los acuerdos previos con las nuevas funcionalidades que las especies y los lugares empiezan a tener en los circuitos ecoturísticos que se vienen implementando en las localidades. Se trata de acuerdos que definen pautas en torno a qué, cuándo, cuánto, dónde y cómo aprovechar esos recursos, de manera que la existencia de esas especies no se vulnere por las acciones de los habitantes de las veredas y de zonas aledañas. Es así que las JAC de Bocas del Raudal y Damas del Nare promueven la idea de que deben alcanzar un adecuado balance entre la preservación de ciertos recursos naturales para el ejercicio del ecoturismo y el aprovechamiento de estos para el desarrollo de sus estrategias tradicionales de sustento o relacionamiento con la naturaleza. Este asunto, no obstante, genera fricciones, y no todos los miembros de las veredas están igualmente dispuestos a participar de esos arreglos comunitarios, en la medida en que no todos se benefician de las actividades ecoturísticas en la misma proporción.

A manera de síntesis comparativa, la tabla 2 expone las principales características que configuran el origen y cambio que han experimentado las relaciones socioecológicas en las dos veredas. 
TABLA 2

COMPARACIÓN DE LAS PRINCIPALES CARACTERÍSTICAS IDENTIFICADAS EN

CADA VEREDA FRENTE A LAS RELACIONES SOCIOECOLÓGICAS ANALIZADAS

\begin{tabular}{|c|c|c|}
\hline $\begin{array}{c}\text { Relaciones } \\
\text { socioecológicas }\end{array}$ & Damas del Nare & Bocas del Raudal \\
\hline $\begin{array}{l}\text { Gente-lugares } \\
\text { (GL) }\end{array}$ & $\begin{array}{l}\text { - Regulación de uso y acceso de lugares con potencial } \\
\text { ecoturístico bajo lógicas promovidas por agencias e } \\
\text { instituciones (p. ej., Secretaría de Turismo, Gobernación del } \\
\text { Guaviare, SENA-Deispaz-CDA). } \\
\text { - Generación de nuevas tensiones relacionadas con el uso y } \\
\text { acceso a recursos comunes y lugares con potencial turístico. } \\
\text { - Reorganización de la distribución espacial de los cultivos } \\
\text { para la adecuación de senderos y zonas de camping para los } \\
\text { turistas. } \\
\text { - Adecuación de las casas para prestar servicios de hospedaje. } \\
\text { - Resignificación de algunos parches de bosque y cuerpos de } \\
\text { agua como atractivos ecoturísticos. } \\
\text { - Revaloración de lugares que rememoran hechos relacionados } \\
\text { con la historia del conflicto y la colonización como atractivos } \\
\text { turísticos. }\end{array}$ & $\begin{array}{l}\text { - Dificultad del acceso a lugares con potencial ecoturístico por } \\
\text { cuenta de las dinámicas del conflicto armado. } \\
\text { - Adecuación de las casas para servicios de hospedaje. } \\
\text { - División entre en el caserío de la vereda y las fincas de la vereda } \\
\text { en relación con las expectativas frente al ecoturismo. } \\
\text { - Resignificación de algunos parches de bosque y cuerpos de agua } \\
\text { como atractivos ecoturísticos. } \\
\text { - Revaloración de lugares que rememoran hechos relacionados con } \\
\text { la historia del conflicto y la colonización como atractivos } \\
\text { turísticos. }\end{array}$ \\
\hline $\begin{array}{l}\text { Gente-especies } \\
\text { (GE) }\end{array}$ & $\begin{array}{l}\text { - Transformación en las valoraciones del delfin rosado como } \\
\text { una especie emblemática para la conservación. } \\
\text { - Revaloración de especies antes vistas como recursos } \\
\text { alimenticios (cacería) y ahora como potenciales atractivos } \\
\text { para el avistamiento de fauna. } \\
\text { - Posicionamiento del avistamiento de aves como uno de los } \\
\text { principales atractivos de la vereda. } \\
\text { - Incremento en la valoración de especies maderables de gran } \\
\text { talla como atractivos paisajísticos, que anteriormente se } \\
\text { utilizaban únicamente para la construcción de casas, cercas y } \\
\text { canoas. }\end{array}$ & $\begin{array}{l}\text { - Revaloración de especies antes vistas como recursos alimenticios } \\
\text { (cacería) y ahora como potenciales atractivos para el avistamiento } \\
\text { de fauna. } \\
\text { - Cambios en las valoraciones de algunas especies cuyos } \\
\text { comportamientos funcionaban como bioindicadores o que se } \\
\text { valoraban como amenazas para los cultivos y ahora se consideran } \\
\text { como importantes para el avistamiento de fauna. } \\
\text { - Posicionamiento del avistamiento de aves como uno de los } \\
\text { principales atractivos de la vereda. }\end{array}$ \\
\hline $\begin{array}{l}\text { Gente-sistemas } \\
\text { productivos (GSP) }\end{array}$ & $\begin{array}{l}\text { - Concepción y fomento del ecoturismo por las instituciones } \\
\text { como una estrategia para la legalización de los sistemas } \\
\text { productivos campesinos y para la reducción de los impactos } \\
\text { ambientales de origen antrópico. } \\
\text { - Expectativas comunitarias frente al turismo como una } \\
\text { estrategia complementaria para diversificar sus fuentes de } \\
\text { ingreso. } \\
\text { - Articulación del ecoturismo en los planes de sustitución } \\
\text { integral de cultivos ilícitos (PNIS). } \\
\text { - Redirección de las actividades productivas hacia la } \\
\text { prestación de servicios turísticos. } \\
\text { - Resignificación del cultivo de coca como una actividad ilegal } \\
\text { y nociva para el ambiente. }\end{array}$ & $\begin{array}{l}\text { - Posicionamiento de la necesidad de un diálogo de las instituciones } \\
\text { estatales con las formas comunitarias de ecoturismo para fortalecer } \\
\text { su papel como estrategia para la legalización de los sistemas } \\
\text { productivos campesinos y para la reducción de los impactos } \\
\text { ambientales de origen antrópico. } \\
\text { - Expectativas comunitarias frente al turismo como una estrategia } \\
\text { complementaria para diversificar sus fuentes de ingreso. } \\
\text { - Articulación de iniciativas turísticas con estrategias de manejo } \\
\text { ambiental en el marco de áreas protegidas (PNN La Macarena, } \\
\text { Zona de Preservación de la Serranía de La Lindosa y Área } \\
\text { Arqueológica Protegida). } \\
\text { - Articulación del ecoturismo con la economía de servicios } \\
\text { existentes en el caserío de la vereda desde décadas anteriores. }\end{array}$ \\
\hline $\begin{array}{l}\text { Gente-ecoturismo } \\
\text { (GET) }\end{array}$ & $\begin{array}{l}\text { - Inicio de actividades ecoturísticas en la década de } 2010 \text {, } \\
\text { impulsadas por las instituciones y los actores locales y } \\
\text { regionales interesados en modelos cooperativos y privados. } \\
\text { - Organización del ecoturismo bajo la forma de empresas } \\
\text { promovidas y formalizadas con la ayuda de instituciones del } \\
\text { nivel departamental y nacional. } \\
\text { - Ecoturismo orientado principalmente a satisfacer intereses } \\
\text { particulares de algunas familias de la vereda, bajo principios } \\
\text { de oferta y demanda. } \\
\text { - Nivel marginal de involucramiento de la JAC en la gestión } \\
\text { del ecoturismo, centrado en la figura del presidente de la } \\
\text { junta y en algunos pocos asociados. } \\
\text { - Nuevas tensiones al interior de la comunidad por cuenta de la } \\
\text { distribución de los réditos del ecoturismo. } \\
\text { - Cambios en el relacionamiento con comunidades indigenas, } \\
\text { vistas ahora como una potencial amenaza para el manejo } \\
\text { sostenible de los atractivos ecoturísticos. } \\
\text { - Generación de nuevas normas comunitarias en el uso de los } \\
\text { recursos naturales. } \\
\text { - Formación de personas de la comunidad para la prestación de } \\
\text { servicios ecoturísticos. } \\
\text { - Aparición de fricciones sociales frente a nuevas normas } \\
\text { comunitarias para el manejo de recursos naturales entre } \\
\text { sectores sociales que se benefician o no del ecoturismo. } \\
\text { - Actividad ecoturística posicionada como una forma } \\
\text { estratégica de gestionar apoyo estatal (a nivel regional y } \\
\text { nacional) y de entidades de cooperación internacional. }\end{array}$ & $\begin{array}{l}\text { - Primeras experiencias en la década de } 1970 \text {, catalogadas bajo el } \\
\text { nombre de "turismo extractivo", asociado a una lógica de } \\
\text { extracción esporádica de recursos a través de la caza y la pesca. } \\
\text { - Proyecto ecoturístico orientado hacia un modelo de manejo } \\
\text { comunitario a través de organizaciones campesinas como } \\
\text { Ecoamem. } \\
\text { - Consolidación del ecoturismo afectado directamente por las } \\
\text { dinámicas del conflicto armado. } \\
\text { - Ecoturismo articulado a una estrategia de consolidación de } \\
\text { propósitos organizativos y políticos comunitarios y orientado a } \\
\text { beneficiar al mayor número de personas de la comunidad. } \\
\text { - Nivel de involucramiento fuerte de la JAC en la gestión del } \\
\text { ecoturismo. } \\
\text { - Formación de personas de la comunidad para la prestación de } \\
\text { servicios ecoturísticos. } \\
\text { - Aparición de fricciones sociales frente a nuevas normas } \\
\text { comunitarias para el manejo de recursos naturales entre sectores } \\
\text { sociales que se benefician o no del ecoturismo. } \\
\text { - Actividad ecoturística posicionada como una forma estratégica de } \\
\text { gestionar apoyo estatal (a nivel regional y nacional) y de entidades } \\
\text { de cooperación internacional. }\end{array}$ \\
\hline
\end{tabular}

Fuente: elaboración propia 


\section{Discusión}

Una comprensión más compleja del ecoturismo puede considerar el análisis de sus implicaciones en las dinámicas socioecológicas desde un enfoque que articule la perspectiva multidimensional y del poder de la ecología política sumado a la perspectiva de la complejidad que caracteriza los sistemas socioecológicos. De esta forma, se pueden identificar alternativas que complementen dos tendencias dominantes en la literatura que analiza estos procesos en torno a los impactos del ecoturismo comunitario: por un lado, a los estudios críticos que identifican al turismo, en general, como parte del proyecto moderno y capitalista y que, así, se convierte en un vector que erosiona tejidos comunitarios y genera procesos de desposesión territorial y degradación ambiental que afectan a las poblaciones locales (Cañada, 20I6). En esta línea, el ecoturismo no resulta ser más que una cara sostenible del turismo convencional que, además, se relaciona con procesos de neoliberalización de la naturaleza (Castree, 2008; Duffy, 2008; Montenegro, 20I4). Por otro lado, se pueden derivar alternativas al enfoque que sostiene que el ecoturismo es una "excusa para prevenir la degradación ambiental” bajo la premisa según la cual esta actividad "abre una oportunidad gana-gana para gestionar la pobreza y los patrones insostenibles de consumo de los recursos locales” (Nepal et al., 2016, p. 7). Cada una de esas tendencias se podría enriquecer al incorporar en sus análisis los diversos matices que adquieren las iniciativas ecoturísticas de acuerdo con las especificidades locales y regionales. De hecho, la experiencia en las veredas analizadas muestra cómo el ecoturismo en una de ellas se ha ajustado para responder a criterios colectivos comunitarios muy marcados a pesar de las tensiones que esto conlleva, mientras que en la otra vereda el ecoturismo, sin dejar de tener visos comunitarios, parece reproducir la senda de una actividad que erosiona y afecta negativamente los procesos colectivos de la comunidad, hecho que ha generado una preocupación en la JAC por implementar estrategias que permitan reforzar el carácter cooperativo con el que inició el ecoturismo en esa vereda. En ambas veredas, y a pesar de las tensiones internas e inevitables, se han logrado arreglos comunitarios sobre cómo regular la interacción de las personas con el medio, especialmente con aquellas especies a las que, desde sus experiencias y expectativas, les han adjudicado un valor ecoturístico, aunque esos arreglos no satisfagan enteramente los variados intereses frente al ecoturismo que se rastrean en cada una de las localidades. De allí la importancia de complementar los enfoques de la ecología política y los sistemas socioecológicos, ya que proveen un marco de análisis y estrategias analíticas para explorar los complejos efectos ecológicos de las acciones humanas sin perder de vista su origen social (Cumming, 20I4). Esta articulación abre un campo de exploración epistemológica y metodológica que puede ser bastante provechoso para generar apuestas transdisciplinarias de investigación que contribuyan en la comprensión compleja y crítica sobre las realidades socioambientales de diversos territorios. La figura 2 expone de manera sintética la articulación del enfoque multidimensional de la ecología política con la intersección de las particularidades ecológicas y sociohistóricas que se abstraen del sistema socioecológico de las veredas analizadas.

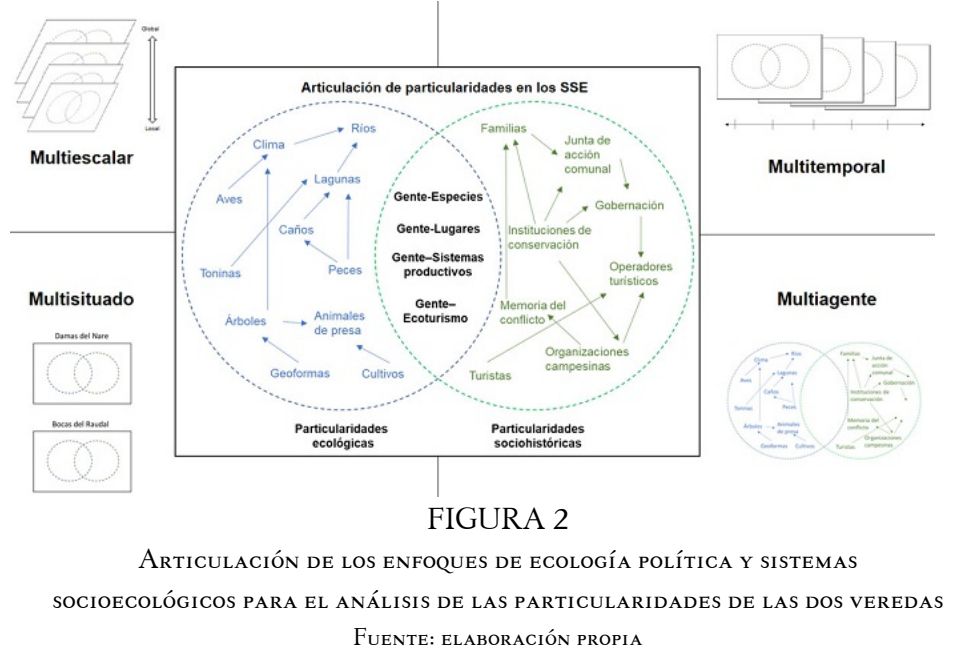




\section{Conclusiones}

Las transformaciones en las relaciones socioecológicas que acompañan el surgimiento del ecoturismo comunitario en las veredas Damas del Nare y Bocas del Raudal destacan tres aspectos principales: primero, la dinamización de las relaciones comunitarias con los ecosistemas; segundo, la resignificación y el reordenamiento de los lugares y los recursos de las veredas en función del ecoturismo, y tercero, el incremento de las relaciones entre sus habitantes e institucionalidades comunitarias con agentes públicos y privados regionales y del orden nacional e internacional.

En cuanto al primer aspecto, las relaciones comunitarias y de estas con los ecosistemas se han comenzado a transformar de formas complejas y multidimensionales. Estas transformaciones articulan cambios paulatinos en las relaciones que mantiene la gente con los sistemas productivos, los lugares y las especies, en función de las actividades ecoturísticas. El ecoturismo está transformando las relaciones comunitarias que se tejen para darle orden a la vida veredal y que se expresan en arreglos puntuales para mantener, por ejemplo, los caminos comunales, las lagunas y las especies que habitan en sus inmediaciones. En una de las veredas, tales arreglos han robustecido redes comunitarias a pesar de que no todos los habitantes ven reflejados en ellos sus intereses particulares, mientras que, en la otra vereda, los nuevos acuerdos de gestión comunal de ciertos recursos vitales para la actividad ecoturística también ocasionan tensiones asociadas a la concentración de beneficios en aquellas familias vinculadas directamente al ecoturismo, hecho que irremediablemente interfiere en las dinámicas de poder a escala local. En torno a esos cambios, también han comenzado a reorganizarse los sistemas de gobernanza que pretenden regular dichos bienes comunes en un contexto en el que se experimenta un reacomodamiento de las relaciones de poder regional por cuenta de la reciente desmovilización de las FARC.

En relación con el segundo aspecto, en ambas localidades se advierte cómo el ecoturismo ha dinamizado cambios en las formas de relacionarse colectivamente con los lugares y bienes de uso común de las veredas. La línea dominante de esos cambios es que se han incorporado acciones y acuerdos con la expectativa de hacer más sostenible su entorno y de establecer relaciones entre los diferentes componentes del medio local para favorecer la protección de ciertas especies (p. ej., las toninas) o lugares particulares (lagunas, raudales, etc.). También se están resignificando viejas prácticas bajo la óptica de un ecoturismo sostenible. Así, por ejemplo, los cultivos de coca empiezan a ser vistos por algunos pobladores como problemáticos en las nuevas narrativas de lo sostenible que empiezan a imponerse en esas localidades y por la degradación ambiental que se les asocia, al tiempo que algunos plantean que viejos cambuches en desuso, que se usaban para el procesamiento de pasta base de coca, pueden adecuarse para satisfacer la curiosidad de turistas ávidos por conocer un renglón de la economía regional que ha sido tan vital durante décadas. Lugares asociados a la guerra que los afectó por tanto tiempo también empiezan a ser resignificados como un vector de reactivación de las memorias locales y de fortalecimiento de su vida comunitaria.

Con respecto al tercer aspecto, para las institucionalidades comunitarias de las veredas, el desarrollo de la actividad ecoturística se ha convertido en una forma eficiente de gestionar recursos y apoyo estatal e incluso internacional, independientemente de las tensiones y desigualdades que su uso y repartición generan al interior de las comunidades veredales. Este incremento en el relacionamiento con instituciones y agentes de otras escalas se da en medio de los nuevos escenarios abiertos con la dejación de las armas por parte de la guerrilla de las FARC, los cuales se han configurado como nuevos contextos para que diferentes instituciones hagan intervenciones en la región, muchas de ellas con el interés de promover programas de legalización de las economías campesinas y de implementación de actividades sostenibles. En este sentido, y a pesar de que los dos escenarios están dentro de áreas protegidas o de reserva forestal, hoy diferentes instituciones públicas y de cooperación internacional promueven el ecoturismo como un vector de legalización y sustentabilidad para las familias campesinas. 
No obstante, los nuevos escenarios que se han abierto en el escenario de construcción de paz y la entrada de nuevas instituciones no han implicado la materialización de una política pública que genere la transformación de las problemáticas estructurales de tipo ambiental y rural que contempla el acuerdo agrario y que, entre otras cosas, pueda llegar a fortalecer el ecoturismo comunitario. Además, la reconfiguración y entrada de nuevos actores armados y el inicio de nuevos ciclos de violencia pueden dificultar seriamente la consolidación de las iniciativas de ecoturismo comunitario ya existentes en el Guaviare.

A partir de esta investigación, también se pueden extraer algunas reflexiones en torno a los retos que depara el desarrollo de este tipo particular de actividad ecoturística para las comunidades y organizaciones interesadas: su legitimidad para cumplir objetivos sociales - en lugar de los efectos negativos que suelen asociarse a ciertas formas de ecoturismo (Carrier y Macleod, 2005; Fletcher y Neves, 20I2) - radica, entre otras cosas, en ampararse y gestionarse desde instituciones comunitarias legítimas (JAC, cabildos indígenas, consejos comunitarios, etc.), en priorizar la distribución equitativa de utilidades y trabajo en su circuito de operación, en plantearse de manera complementaria con otras actividades agropecuarias que promuevan la soberanía alimentaria, en mantener un diálogo con instituciones estatales y de cooperación internacional que no vulnere la autonomía local y en estructurarse a partir de ejercicios de ordenamiento territorial comunitario para reglamentar el uso, la distribución y el acceso a bienes para la prestación del servicio ecoturístico. La base de todo este proceso de construcción comunitaria que puede tejerse en torno al ecoturismo radica, sin lugar a dudas y como lo señala Devine (20I6), "en quién posee los medios de producción, en otras palabras, quién decide qué relaciones sociales que definen la cultura y el lugar se mercantilizan y cómo" (p. I4).

Los casos analizados demuestran la importancia de situar crítica y contextualmente la comprensión de los efectos que trae la actividad ecoturística, en escenarios regionales marcados por la violencia y la inequidad histórica de familias campesinas que por décadas han intentado ganarse su derecho a la vida digna y a la propiedad en zonas de frontera. Además, como señala Cobbinah (2015), "es necesario comprender cómo el ecoturismo es practicado en la comunidad local” (p. 179) para superar la imposición de percepciones foráneas sobre este, que a menudo operan a través de dispositivos institucionales y económicos. La articulación de enfoques entre la ecología política y los sistemas socioecológicos potencia la comprensión crítica, comparativa y contextualizada de esos efectos.

Nuestra propuesta no agota la diversidad de abordajes que albergan tales enfoques, solo expone algunas de las potencialidades y limitaciones que identificamos en la comprensión del ecoturismo comunitario como un vector de constitución y transformación de las dinámicas socioecológicas, en un contexto complejo de marginalidad social, ilegibilidad política e intervención estatal.

\section{Referencias.}

Acosta, L. (1993). Guaviare. Puente a la Amazonia. Bogotá: Corporación Araracuara.

Aguilar-Garavito, M., y Ramírez, W. (2015). Monitoreo a procesos de restauración ecológica aplicado a ecosistemas terrestres. Bogotá: Instituto de Investigación de Recursos Biológicos Alexander von Humboldt.

Álvarez Uribe, M. C., Mancilla López, L. P., y Cortés Torres, J. E. (2007). Caracterización socioeconómica y seguridad alimentaria de los hogares productores de alimentos para el autoconsumo, Antioquia-Colombia. Agroalimentaria, I2(25), I09-I22. Recuperado de https://www.scielo.org.ve/scielo.php?script=sci_arttext\&pi $\mathrm{d}=\mathrm{S}_{1316-03542007000200008}$

Becker, E. (20I2). Social-ecological systems as epistemic objects. En M. Glaser, G. Krause, B. M. W. Ratter y M. Welp (eds.), Human-nature interactions in the anthropocene: Potentials of social-ecological systems analysis (pp. 37-59). Londres: Routledge. 
Biersack, A. (2006). Reimagining political ecology: Culture/power/history/nature. En A. Biersack y J. Greenberg (eds.), Reimagining political ecology (pp. 3-40). Durham: Duke University Press.

Binder, C., Hinkel, J., Bots, W., y Pahl-Wostl, C. (2013). Comparison of frameworks for analyzing social-ecological systems. Ecology and Society, I8(4), I-26. https://www.dx.doi.org/I0.575I/ES-0555I-I80426

Blaser, M., y Escobar, A. (2016). Political ecology. En J. Adamson, W. A. Gleason y D. N. Pellow (eds.), Keywords in the study of environment and culture (pp. 164-167). Nueva York: New York University Press.

Boley, B., y Green, G. (2015). Ecotourism and natural resource conservation: The 'potential' for a sustainable symbiotic relationship. Journal of Ecotourism, I5(I), 36-50. https://www.doi.org/10.1080/14724049.2015.1094 080

Boonstra, W. (20I6). Conceptualizing power to study social-ecological interactions. Ecology and Society, 2I(I), I-2I. https://www.dx.doi.org/10.575I/ES-07966-210I2I

Bridge, G., McCarthy, J., y Perreault, T. (2015). Editor’s introduction. En T. Perrault, G. Bridge y J. McCarthy (eds.), The Routledge handbook of political ecology (pp. 3-18). Nueva York: Routledge.

Burns, P. (1999). An introduction to tourism and anthropology. Londres: Routledge.

Cañada, E. (2016). Implicaciones socioambientales de la construcción del espacio turístico. Ecología Política, (52), I2-I6. Recuperado de https://www.ecologiapolitica.info/?p=67II

Capra, F., y Cempau, D. (1998). La trama de la vida. Barcelona: Anagrama.

Cárdenas, D., Castaño, N., Zubieta, M., y Jaramillo, M. (2008). Flora de las formaciones rocosas de la Serranía de La Lindosa. Bogotá: Instituto Amazónico de Investigaciones Científicas (Sinchi).

Carrier, J., y Macleod, D. (2005). Bursting the bubble: The socio-cultural context of ecotourism. Journal of the Royal Anthropological Institute, II(2), 315-334. https://www.doi.org/I0.IIII/j.I467-9655.2005.00238.x

Castree, N. (2008). Neoliberalising nature: The logics of deregulation and reregulation. Environment and Planning A, 40(I), I3I-I52. https://www.doi.org/10.1068/a3999

Cawley, M., y Conway, T. (2016). Defining ecotourism: Evidence of provider perspectives from an emerging area. Journal of Ecotourism, 15(2), I22-138. https://www.doi.org/I0.1080/14724049.2016.1153105

Chuvieco, E. (1996). Fundamentos de teledetección espacial. Madrid: Ediciones Rialp.

Cobbinah, P. (2015). Contextualizing the meaning of ecotourism. Tourism Management Perspectives, I6, I79-189. https://www.doi.org/10.1016/j.tmp.2015.07.015

Cumming, G. (20I4). Theoretical frameworks for the analysis of social-ecological systems. En S. Sakai y C. Umetsu, Social-ecological systems in transition (pp. 3-18). Tokio: Springer.

Dávalos, L., Bejarano, A., y Correa, L. (2008). Disabusing cocaine: Pervasive myths and enduring realities of a globalised commodity. International Journal of Drug Policy, 20(5), 381-386. https://www.doi.org/I0.1016/j.

drugpo.2008.08.007

Defensoría del Pueblo. (2017). Informe de riesgo n.o 025-17 A.I. Bogotá: autora.

Del Cairo, C., Montenegro-Perini, I., y Vélez, J. (20I4). Naturalezas, subjetividades y políticas ambientales en el noroccidente amazónico. Boletín de Antropología, 29(48), 13-40. Recuperado de https://www.aprendeenlin ea.udea.edu.co/revistas/index.php/boletin/article/view/22213

Devine, J. (2016). Colonizing space and commodifying place: Tourism's violent geographies. Journal of Sustainable Tourism, 25(5), I-I7. https://www.doi.org/I0.I080/09669582.20I6.I226849

Dove, M. (2006). Indigenous people and environmental politics. Annual Review of Anthropology, 35, 19I-208. ht tps://www.doi.org/I0.II46/annurev.anthro.35.081705.123235 
Dressler, W., Büscher, B., Schoon, M., Brockington, D., Hayes, T., Kull, C., y Shrestha, K. (20I0). From hope to crisis and back again? A critical history of the global CBNRM narrative. Environmental Conservation, 37(I), 5-15. https://www.doi.org/10.1017/S0376892910000044

Duffy, R. (2008). Neoliberalising nature: Global networks and ecotourism development in Madagascar. Journal of Sustainable Tourism, I6(3), 327-344. https://www.doi.org/10.1080/09669580802154124

Escalera, J., y Ruiz, E. (20II). Resiliencia socioecológica: aportaciones y retos desde la antropología. Revista de Antropología Social, 20, I09-135. Recuperado de https://www.revistas.ucm.es/index.php/RASO/article/vi ew/36264

Fabinyi, M., Evans, L., y Foale, S. J. (20I4). Social-ecological systems, social diversity, and power: Insights from anthropology and political ecology. Ecology and Society, 19(4), I-28. https://www.dx.doi.org/10.575I/ES-07 029-190428

Fajardo, D., y Salgado, H. (2017). El acuerdo agrario. Bogotá: Aurora.

Fletcher, R., y Neves, K. (20I2). Contradictions in tourism: The promise and pitfalls of ecotourism as a manifold capitalist fix. Environment and Society: Advances in Research, 3(I), 60-77. https://www.dx.doi.org/I0.3167 $/$ ares.2012.030105

Folke, C., Carpenter, S., Elmqvist, T., Gunderson, L., Holling, C. S., y Walker, B. (2002). Resilience and sustainable development: Building adaptive capacity in a world of transformations. Ambio: A Journal of the Human Environment, 31(5), 437-440. Recuperado de https://www.ncbi.nlm.nih.gov/pubmed/12374053

Guber, R. (200I). La etnografía. Método, campo y reflexividad. Bogotá: Norma.

Guedes, E. (2004). Mapeo de actores sociales: un enfoque de redes sociales en el marco del desarrollo local. Montevideo: Universidad de la República.

Guilland, M., y Ojeda, D. (2013). Indígenas “auténticos” y campesinos “verdes”. Los imperativos identitarios del turismo en Colombia. Cahiers des Amériques Latines, (7I), ing-I44. Recuperado de https://www.journals.o penedition.org/cal/2689

Holling, C. (1973). Resilience and stability of ecological systems. Annual Review of Ecology and Systematics, 4, I-23. https://www.doi.org/I0.II46/annurev.es.04.II0I73.000245

Holling, C. (200I). Understanding the complexity of economic, ecological, and social systems. Ecosystems, 4(5), 390-405. https://doi.org/10.1007/s1002I-00-010I-5

Jaramillo, J., Castro-Herrera, J., Zambrano, E. R., y Ortiz, D. (2018). La institucionalidad comunitaria para la paz en Barrancabermeja: la experiencia de Apall y Asopesamm. En J. Jaramillo, J. Castro-Herrera y D. Ortiz (eds.), Instituciones comunitarias para la paz en Colombia. Esbozos teóricos, experiencias locales y desafíos sociales (pp. II9-152). Bogotá: Universidad Nacional de Colombia.

Jaramillo, J., Castro-Herrera, J., y Ortiz, D. (2018). Las instituciones comunitarias para la paz en Colombia: esbozos teóricos y dimensiones analíticas. En J. Jaramillo, J. Castro-Herrera y D. Ortiz (eds.), Instituciones comunitarias para la paz en Colombia. Esbozos teóricos, experiencias locales y desafíos sociales (pp. 25-58). Bogotá: Universidad Nacional de Colombia.

Kitzinger, J. (1995). Qualitative research: Introducing focus group. BMJ, (31I), 299-302. https://www.doi.org/I0.I I36/bmj.311.7000.299

Latour, B. (2008). Reensamblar lo social. Una introducción a la teoría del actor-red. Buenos Aires: Manantial.

Magome, H., y Fabricius, C. (2004). Reconciling biodiversity conservation with rural development: The Holy Grail of CBNRM? En C. Fabricius, E. Koch, H. Magome y S. Turner (eds.), Rights, resources and rural 
development: Community-based natural resource management in Southern Africa (pp. 93-II4). Londres: Routledge.

McGinnis, M., y E, Ostrom. (2014). Social-ecological system framework: Initial changes and continuing challenges. Ecology and Society, I9(2), I-30. https://www.dx.doi.org/10.575I/ES-06387-190230

Melo, L., y Camacho, M. (2005). Adaptación de la metodología Corine Land Cover para Colombia. Revista Análisis Geográfico, (29), 22-36.

Ministerio de Agricultura y Desarrollo Rural. (28 de mayo de 2017). Decreto 893 de 2017, por el cual se crean los Programas de Desarrollo con Enfoque Territorial-PDET. Recuperado de https://www.es.presidencia.gov.co /normativa/normativa/DECRETO\%20893\%20DEL\%2028\%20DE\%20MAYO\%20DE\%202017.pdf

Ministerio de Comercio, Industria y Turismo. (2016). Plan Sectorial de Turismo “Turismo para la construcción de paz” 20I4-20I8. Bogotá: autor. Recuperado de https://www.citur.linktic.com/upload/publications/docume ntos/155.Plan_sectorial_de_turismo_2014_2018.pdf

Molano, A. (1987). Selva adentro. Una historia oral de la colonización del Guaviare. Bogotá: El Áncora Editores.

Montenegro, I. (20I4). El ecoturismo en juego: procesos de neoliberalización, tecnologías de gobierno y agencias campesinas en Playa Güío, Guaviare (Tesis de pregrado). Pontificia Universidad Javeriana, Bogotá.

Moran, E. (20II). Environmental social science. Human-environment interactions and sustainability. Londres: Wiley-Blackwell.

Mostafanezhad, M., Norum, R., Shelton, E., y Thompson-Carr, A. (2016). Political ecology of tourism. Community, power and the environment. Nueva York: Routledge.

Nepal, S., Saarinen, J., y McLean-Purdon, E. (2016). Introduction. Political ecology and tourism: Concepts and constructs. En S. Nepal y J. Saarinen (eds.), Political ecology and tourism (pp. I-15). Londres: Routledge. Recuperado de https://www.researchgate.net/publication/309904546_Introduction_Political_ecology_and_t ourism___concepts_and_constructs

Newell, B., Crumley, C. L., Hassan, N., Lambin, E. F., Pahl-Wostl, C., Underdal, A., y Wasson, R. (2005). A conceptual template for integrative human-environment research. Global Environmental Change, ${ }_{15}(4)$, 299-307. https://www.doi.org/I0.10I6/j.gloenvcha.2005.06.003

Nightingale, A., y Cote, M. (20I2). Resilience thinking meets social theory: Situating social change in socioecological systems (SES) research. Progress in Human Geography, 36(4), 475-489. https://www.doi.org/I0.I 177/0309132511425708

Observatorio de Seguimiento a la Implementación del Acuerdo de Paz. (2017). ¿Es posible una paz estable y duradera sin cumplir el Acuerdo Final? [Boletín 004]. Bogotá: autor. Recuperado de https://www.rebelion .org/docs/232422.pdf

Oficina en Washington para Asuntos Latinoamericanos, e Instituto de Estudios para el Desarrollo y la Paz. (2009). La aspersión aérea de cultivos de uso ilícito en Colombia: una estrategia fallida. Bogotá: autores. Recuperado de https://www.mamacoca.org/docs_de_base/Fumigas/Aspersion_Una_estrategia_Fallida_Ya mile_Salinas_WOLA_2009.pdf

Ojeda, D. (2012). Green pretexts: Ecotourism, neoliberal conservation and land grabbing in Tayrona National Natural Park, Colombia. Journal of Peasant Studies, 39(2), 357-375. https://www.doi.org/10.1080/03066150. 2012.658777

Organización Mundial del Turismo [OMT]. (1999). Sostenibilidad y competitividad: técnicas, procedimientos y métodos. Autor. 
Organización Mundial del Turismo [OMT]. (2004). Indicators of sustainable development for tourism destinations: A guidebook. Madrid: autor.

Ortiz, D. (2016). Las políticas de desarrollo alternativo en el Guaviare: formación local del Estado y producción estatal del espacio (Tesis de pregrado). Pontificia Universidad Javeriana, Bogotá.

Ostrom, E. (1990). Governing the commons: The evolution of institutions for collective action. Nueva York: Cambridge University Press.

Ostrom, E. (2009). A general framework for analyzing sustainability of social-ecological systems. Science, 325(5939), 419-422. https://www.doi.org/10.II26/science.II72133

Peres, C. (1999). General guidelines for standardizing line-transect surveys of tropical forest primates. Neotropical Primates, 7(I), II-I6. Recuperado de https://www.researchgate.net/publication/228988485_General_Guidelin es_for_standardizing_line-transect_surveys_of_tropical_forest_primates

Pérez, M. (2004). Impacto ambiental del turismo. En Manual de turismo sostenible (pp. 62-83). Madrid: MundiPrensa.

Presidencia de la República de Colombia. (29 de mayo de 2017). Decreto 896 de 2017, por el cual se crea el Programa Nacional Integral de Sustitución de Cultivos de Uso Ilícito-PNIS. Recuperado de https://www.es.presidencia.gov.co/normativa/normativa/DECRETO\%20896\%20DEL\%2 029\%20DE\%20MAYO\%20DE\%202017.pdf

Restrepo, E. (2016). Etnografía: alcances, técnicas y éticas. Popayán: Envión.

Robbins, P. (2012). Political ecology. Malden: Wiley-Blackwell.

Salazar, N. (2006). Antropologi\#a del turismo en países en desarrollo: ana\#lisis cri\#tico de las culturas, poderes e identidades generados por el turismo. Tabula Rasa, (5), 99-128. Recuperdo de https://www.revistatabular asa.org/numero-5/salazar.pdf

Schoon, M., y van der Leeuw, S. (2015). The shift toward social-ecological systems perspectives: Insights into the human-nature relationship. Natures, Sciences, Sociétés, 23, 166-174. Recuperado de https://www.cairn.in fo/revue-natures-sciences-societes-2015-2-page-I66.htm

Schulte, S. (2003). La planificación estratégica del turismo. En S. Schulte, Guía conceptual metodológica para el desarrollo y la planificación del sector turismo (pp. 57-75). Santiago: Ilpes y Cepal. Recuperado de https://w ww.repositorio.cepal.org/bitstream/handle/I1362/5589/I/S2003705_es.pdf

Stronza, A. (2008). The bold agenda of ecotourism. En A. Stronza y W. Durham, Ecotourism and conservation in the Americas (pp. 3-17). Cambridge: CABI.

Torres, I., Rátiva, S., y Varela, D. (20I2). Cartografía social como metodología participativa y colaborativa de investigación en el territorio afrodescendiente de la cuenca alta del río Cauca. Cuadernos de Geografía: Revista Colombiana de Geografía, 2I(2), 59-73. https://www.doi.org/ro.15446/rcdg.v2In2.25774

Trinh, T., Nguyen, X., y Rastall, R. (2016). Participatory biodiversity monitoring: Methodological guidance. Hanói: SNV Netherlands Development Organisation.

Turner, M. (2014). Political ecology I: An alliance with resilience? Progress in Human Geography, 38(4), 616-623. https://www.doi.org/ı0.II77/0309132513502770

Vayda, A. P., y Walters, B. B. (1999). Against political ecology. Human Ecology, 27(I), 167-179. Recuperado de http s://www.faculty.bemidjistate.edu/mlawrence/Vayda\%20and\%20Walters.pdf

Villamizar, P. A. (2017). Turismo y paz: una apuesta para el desarrollo en la región de Urabá-Darién. Opera, (20), 107-I27. https://www.doi.org/10.1860I/16578651.n20.06 
West, P. (2006). Conservation is our government now. The politics of ecology in Papua New Guinea. Durham: Duke University Press.

Wolf, E. (2006). Europa y la gente sin historia. Ciudad de México: Fondo de Cultura Económica.

\section{Notas}

* Artículo de investigación que parte de los resultados obtenidos en dos proyectos de investigación (ID 7463 e ID 8014) financiados por la convocatoria Laudato Si' (2016 y 2017) de la Vicerrectoría de Investigación de la Pontificia Universidad Javeriana.

Licencia Creative Commons CC BY-4.0 